\title{
DFT Study of the Reaction Mechanism of $N$-(Carbomylcarbamothioyl) Benzamide
}

\author{
Felix Odame \\ Department of Chemistry, Nelson Mandela University, P.O. Box 77000, Port Elizabeth 6031, South Africa \\ * Corresponding author: E-mail: felixessah15@gmail.com(FO) \\ Tel.: +27836660784, Fax: +2741 5044236.
}

Received: 13-11-2017

\begin{abstract}
The reaction mechanism for the formation of $N$-(carbomylcarbamothioyl)benzamide has been successfully computed with the B3LYP/6-31g(d) functional and basis set and compared with ${ }^{1} \mathrm{H}$ NMR monitoring of the progress of the reaction with time. The reaction is proposed to proceed through two transition states: Ts1 (the rate-determining step) with highly unstable species (with a requisite orientation for the reaction to proceed), and Ts2 with a lower energy leading to the product. Computation of the reaction pathway was also carried out using the B3PW91/6-31G(d), M06/6-31G(d) and $\mathrm{Wb} 97 \mathrm{XD} / 6-31 \mathrm{G}(\mathrm{d})$ functionals and basis set. These results do not present a clear reaction pathway compared to that given by the B3LYP/6-31G(d).
\end{abstract}

Keywords: Transition state; imaginary frequency; urea, reaction mechanism; benzoyl isothiocyanate.

\section{Introduction}

The use of Density functional theory (DFT) in computation in most branches of chemistry over the years has been extensive, ${ }^{1-3}$ and various methods have been used in that regard, ${ }^{4-8}$ the methods used include local density approximation (LDA), generalized gradient approximation (GGA), meta GGA, hybrid GGA, hybrid-meta GGA, and double-hybrid GGA, various empirical corrections such as dispersion, have been successfully implemented in many popular computational codes. By the use of standard functional approximation and standard basis set, the theoretical calculation of the electronic structure and energetics of chemical interest are easily computed. B3LYP, which is a global hybrid GGA and has been used extensively in most areas of chemistry. It is a hybrid of exact Hartree-Fock exchange with local and semi-local exchange and correlation terms on the basis of the adiabatic connection, ${ }^{9-14}$ In this work, the use of different DFT methods to compute the reaction mechanism for the synthesis of $\mathrm{N}$-(carbomylcarbamothioyl) benzamide has been explored.

The mechanisms for the oxidation of thiophene by $\mathrm{OH}$ radicals under inert conditions (Ar) have been studied using density functional theory in conjunction with various exchange-correlation functionals. ${ }^{15} \mathrm{~A}$ density functional theory (DFT) study has been performed to explore the mechanisms of the acid catalyzed decarboxylation reaction of salicylic acids using the B3LYP method with $6-31++G(d, p)$ basis set in both gas phase and aqueous environment. ${ }^{16}$ Density functional theory (DFT) has been used to study the cobalt(I)-catalyzed enantioselective intramolecular hydroacylation of ketones and alkenes. Hydrogen migration was both the rate determining and chirality-limiting step, and this step was endothermic. Reductive elimination was the rate-determining step, but the chirality-limiting step was hydrogen migration, which occurred easily. The results also indicated that the alkene hydroacylation leading to (S)indanone formation was more energetically favourable than the ketone hydroacylation that gave (R)-phthalide, both thermodynamically and kinetically. ${ }^{17}$

The reaction mechanisms of $\mathrm{H}_{2}$ with OCS have been investigated theoretically by using density function theory method. Three possible pathways leading to major products $\mathrm{CO}$ and $\mathrm{H}_{2} \mathrm{~S}$, as well as two possible pathways leading to by-product $\mathrm{CH}_{4}$ have been proposed and discussed. The structure parameters, vibrational frequencies and energies for each stationary point were calculated, and the corresponding reaction mechanism given by the potential energy surface determined from the relative energies. ${ }^{18}$ Though a lot of computational effort has been expended on different reaction systems much has not been done on the reaction mechanisms of thiones with amines. 
In this work we present the computed reaction mechanism and the DFT transition state studies of the formation of $\mathrm{N}$-(carbomylcarbamothioyl) benzamide, the transition states that contribute to the formation of products as well as the intermediates in the reaction pathway have been computed and discussed.

\section{Computational Details}

The reactants, transition states, intermediates and products structures were fully optimized at the B3LYP/6-31G(d). When compared with other levels of theory, the B3LYP method was sufficiently accurate for predicting reliable geometries and frequencies of the stationary points. ${ }^{19-22}$ Computation of vibrational frequency based on the optimized geometry of each reactant, transition structure, intermediate and product was carried out. All reactants, intermediates and products had no imaginary frequencies, whereas each transition state had one and only one imaginary frequency. The intrinsic reaction coordinate (IRC) ${ }^{23-25}$ calculations, were performed at the same level of theory to ensure that the transition states lead to the expected reactants and products. The computations were carried out using the GAUSSIAN 09 program package, ${ }^{26}$ with Gausview 4.1 as the software for preparing the files whilst the HOMO-LUMO diagrams were generated using Avogadro.

\section{Results and Discussion} follows.

The species used for the computations are defined as

I1 = initial starting material

Ts1 = first transition state and highest energy specie
P1 = Intermediate

TS1 $=$ Second transition state

P2 = final product.

The predicted reaction pathway proceeds by the coming together of urea and benzoyl isothiocyanate (I1), it was obtained by optimising the starting material to a minimum and also tracing the reverse intrinsic reaction coordinate (IRC) path of the transition state TS1. The starting materials were initially minimized using the B3LYP functional and the 6-31g (d) basis set. The two species (I1) together have no charge and a dipole moment of 2.1286 Debye. At the onset of the attack of the thiocyanate carbon by an amine group of urea, the distance between the carbon of the thione and the amine was $3.70191 \AA$. In the determination of energy profile, I1 was used as the point of reference. A transition state Ts1 was computed using both the B3LYP functional at the $6-31 \mathrm{~g}(\mathrm{~d})$ basis set, this gave a dipole moment of 10.2126 Debye and a relative free energy of $+40.23 \mathrm{kcal} / \mathrm{mol}$. TS1 is singlet species of no charge, It is a saddle point with a single imaginary frequency, obtained according to the Berny algorithm and subsequent vibrational analysis. The high energy barrier of Ts1 is consistent with the fact that it is the rate determining step. This is the step that involves attaining the right orientation for attack of the thione carbon by the lone pair of electrons on the nitrogen of the urea. A forward IRC computation and optimization of the species obtained gave $\mathbf{P 1}$ which is a singlet species of no charge with a dipole moment of 3.7226 Debye. The relative free energy of P1 is $-0.66 \mathrm{kcal} / \mathrm{mol}$. The formation of the $\mathrm{C}-\mathrm{N}$ bond in $\mathbf{P 1}$ using the thione carbon leads to the formation of TS2 which is also a singlet species with a charge of 2 and a dipole moment of 9.3700 Debye. TS2 is a saddle point with a single imaginary frequency. The relative free energy of TS2 is $13.62 \mathrm{kcal} / \mathrm{mol}$. A forward IRC pathway from TS2 gives P2 which is a singlet species of no charge, and an imaginary

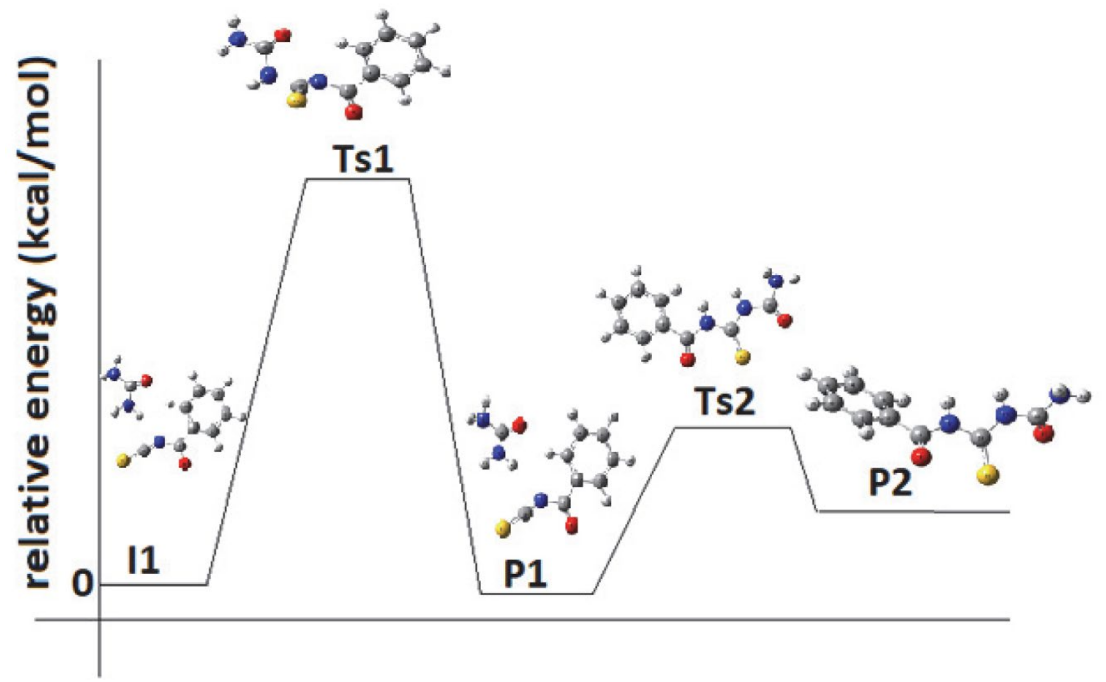

Figure 1. The potential energy surface of the formation of $N$-(carbomylcarbamothioyl) benzamide computed using the B3LYP/6-31g(d) level of theory. 
frequency of zero. The dipole moment of $\mathbf{P 2}$ is 7.7072 Debye. $\mathbf{P 2}$ is the product of the reaction and this consistent with experimentally obtained product. The relative free energy of $\mathbf{P} 2$ was $10.04 \mathrm{kcal} / \mathrm{mol}$. Figure 1 gives the potential energy surface of the formation of $\mathrm{N}$-(carbomylcarbamothioyl)benzamide computed using the B3LYP functional and $6-31 \mathrm{~g}(\mathrm{~d})$ basis set and the corresponding optimized conformation of the intermediates and transition states in gas phase for the formation of $\mathrm{N}$-(carbomylcarbamothioyl)benzamide. All the other functionals used for this computation (B3PW91, M06 and wB97XD) gave inconsistent results hence a good potential energy surface could not be obtained.

The bond length has been computed for all the species. Table 1 gives the bond angles of starting species, intermediates, transition states and the products for the re-

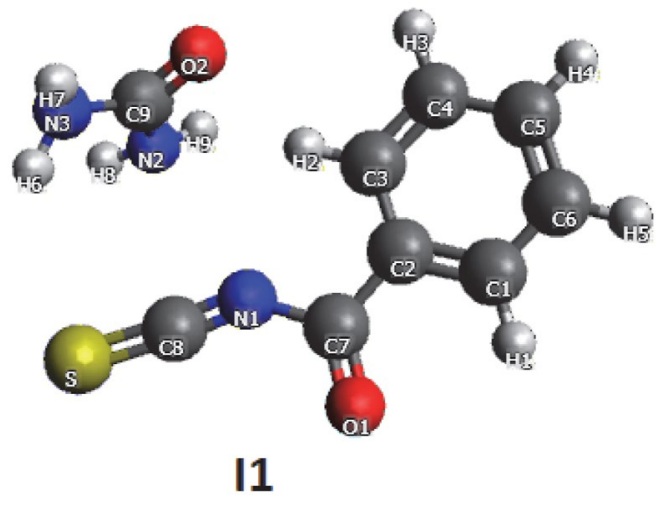

Figure 2. Structure of I1 with enlarged numbering for clarity. action. The bond distances of the atoms in the aromatic range are approximately equal whilst the bond lengths of the groups that are at the site of activity or directly attached to the site of activity undergo significant changes in most cases. Whilst table 2 gives the compiled results of the computed reaction pathway using the B3PW91/6-31G(d), M06/6-31G(d) and Wb97XD/6-31G(d) functionals and basis set. These results do not present a clear reaction path way as given by the B3LYP/6-31G(d).

Figure 2 gives the structure of $\mathbf{I} 1$ with enlarged numbering for clarity.

Table 1. Comparison of the bond lengths of the starting species, intermediates, transition states and products.

\begin{tabular}{lccccc}
\hline Bond length/A & I1 & Ts1 & P1 & Ts2 & P2 \\
\hline 02-C9 & 1.23 & 1.20 & 1.23 & 1.21 & 1.21 \\
C8-S & 1.58 & 1.67 & 1.57 & 1.64 & 1.634 \\
N3-C9 & 1.39 & 1.36 & 1.39 & 1.40 & 1.39 \\
C4-C3 & 1.39 & 1.39 & 1.39 & 1.40 & 1.40 \\
C4-C5 & 1.40 & 1.40 & 1.40 & 1.40 & 1.40 \\
C3-C2 & 1.40 & 1.40 & 1.40 & 1.40 & 1.40 \\
C8-N1 & 1.20 & 1.27 & 1.21 & 1.40 & 1.40 \\
C5-C6 & 1.40 & 1.40 & 1.40 & 1.40 & 1.40 \\
N1-C7 & 1.43 & 1.41 & 1.44 & 1.41 & 1.41 \\
C2-C7 & 1.48 & 1.49 & 1.48 & 1.50 & 1.50 \\
C2-C1 & 1.41 & 1.40 & 1.41 & 1.40 & 1.41 \\
C7-01 & 1.21 & 1.22 & 1.21 & 1.21 & 1.21 \\
C6-C1 & 1.39 & 1.39 & 1.39 & 1.39 & 1.39 \\
C9-N2 & 1.38 & 1.51 & 1.39 & 1.42 & 1.42 \\
N2-C8 & 3.70 & 1.66 & 3.66 & 1.401 & 1.39 \\
\hline
\end{tabular}

Table 2. Compiled results from the computation of the reaction mechanism using the B3PW91/6-31G(d), M06/6-31G(d) and Wb97XD/6-31G(d) functionals and basis set.

\begin{tabular}{lrcccc}
\hline Species & $\begin{array}{c}\text { Dipole } \\
\text { moment }\end{array}$ & $\begin{array}{c}\text { Imaginery } \\
\text { frequency }\end{array}$ & $\begin{array}{c}\text { Free } \\
\text { Energies }\end{array}$ & $\begin{array}{c}\text { Change in } \\
\text { entropy (hartrees) }\end{array}$ & $\begin{array}{c}\text { Change in } \\
\text { entropy (kcal/mol) }\end{array}$ \\
\hline I1 & 4.89 & 0 & -1060.862 & 0 & \\
TS1 & 10.39 & 1 & -1060.798 & 0.063 & 0 \\
P1 & 5.16 & 0 & -1060.819 & 0.043 & 27.07 \\
TS2 & 9.24 & 1 & -1060.844 & 0.017 & 10.82 \\
P2 & 12.29 & 0 & -1060.877 & -0.015 & -9.28 \\
\hline & & M3PW91/6-31G(d) & \\
\hline I1 & 2.83 & 0 & -1060.734 & 0 & 0 \\
Ts1 & 3.52 & 1 & -1060.717 & 0.017 & 10.42 \\
P1 & 5.37 & 0 & -1060.676 & 0.057 & 35.88 \\
Ts2 & 9.25 & 1 & -1060.701 & 0.033 & -0.67 \\
P2 & 12.05 & 0 & -1060.734 & -0.0003 & \\
\hline & & & & & \\
\hline I1 & 3.74 & 0 & -1060.940 & 0 & 0.19 \\
Ts1 & 10.73 & 1 & -1060.865 & 0.075 & -0.684 \\
P1 & 2.11 & 0 & -1060.941 & 0.001 & 4.18 \\
Ts2 & 6.19 & 1 & -1060.933 & 0.007 & 5.09 \\
P2 & 9.33 & 0 & -1060.932 & 0.008 & \\
\hline
\end{tabular}




\section{HOMO-LUMO Analysis}

Table 3 gives the frontier orbitals for all the species in the reaction pathway computed using the B3PLYP functional at the $6-31 \mathrm{~g}(\mathrm{~d})$ basis set. The HOMO-LUMO gaps showed that there is consistency in the information obtained from the HOMO-LUMO gaps of the different species. For I1 the gap was $0.17727 \mathrm{eV}$ this is consistent with high energy barrier hence heat or any other source of energy to help to form the Ts1 with a HOMO-LUMO gap of $0.17424 \mathrm{eV}$, the HOMO-LUMO gap obtained for P1 was $0.17881 \mathrm{eV}$ this narrows to $0.13336 \mathrm{eV}$ in Ts1 with the final product $\mathbf{P 2}$ giving a HOMO-LUMO gap of $0.14175 \mathrm{eV}$.
Figure 3 gives the ${ }^{1} \mathrm{H}$ NMR monitoring of the reaction over a 3 hour period at 30 minute intervals. The amino group gets attached after 30 minutes with the amino group changing environment upon attachment hence the disappearance of the signal at $4.50 \mathrm{ppm}$ with time, whilst the signal at $12.00 \mathrm{ppm}$ increases in intensity with time.

\section{Conclusion}

The reaction mechanism of $N$-(carbomylcarbamothioyl)benzamide has been successfully computed with B3LYP/6-31g(d). The reaction is proposed to proceed through two transition states Ts1 (the rate determining

Table 3. Frontier orbitals of reacting species, transition states, intermediates and product computed using B3LYP/6-3

\begin{tabular}{lrrrrr}
\hline & I1/eV & Ts1/eV & P1/eV & Ts2/eV & P2/eV \\
\hline LUMO+4 & -0.044 & 0.010 & 0.043 & 0.035 & 0.040 \\
LUMO+3 & -0.005 & 0.005 & -0.004 & 0.022 & 0.027 \\
LUMO+2 & -0.013 & -0.006 & -0.013 & -0.022 & -0.021 \\
LUMO+1 & -0.041 & -0.033 & -0.047 & -0.031 & -0.034 \\
LUMO & -0.081 & -0.034 & -0.080 & -0.064 & -0.069 \\
HOMO & -0.258 & -0.208 & -0.259 & -0.198 & -0.210 \\
HOMO-1 & -0.261 & -0.213 & -0.261 & -0.240 & -0.237 \\
HOMO-2 & -0.264 & -0.240 & -0.262 & -0.266 & -0.265 \\
HOMO-3 & -0.269 & -0.241 & -0.270 & -0.274 & -0.271 \\
HOMO-4 & -0.276 & -0.242 & -0.277 & -0.277 & -0.274 \\
HOMO-LUMO GAP $(\mathrm{eV})$ & 0.177 & 0.174 & 0.179 & 0.133 & 0.142 \\
\hline
\end{tabular}

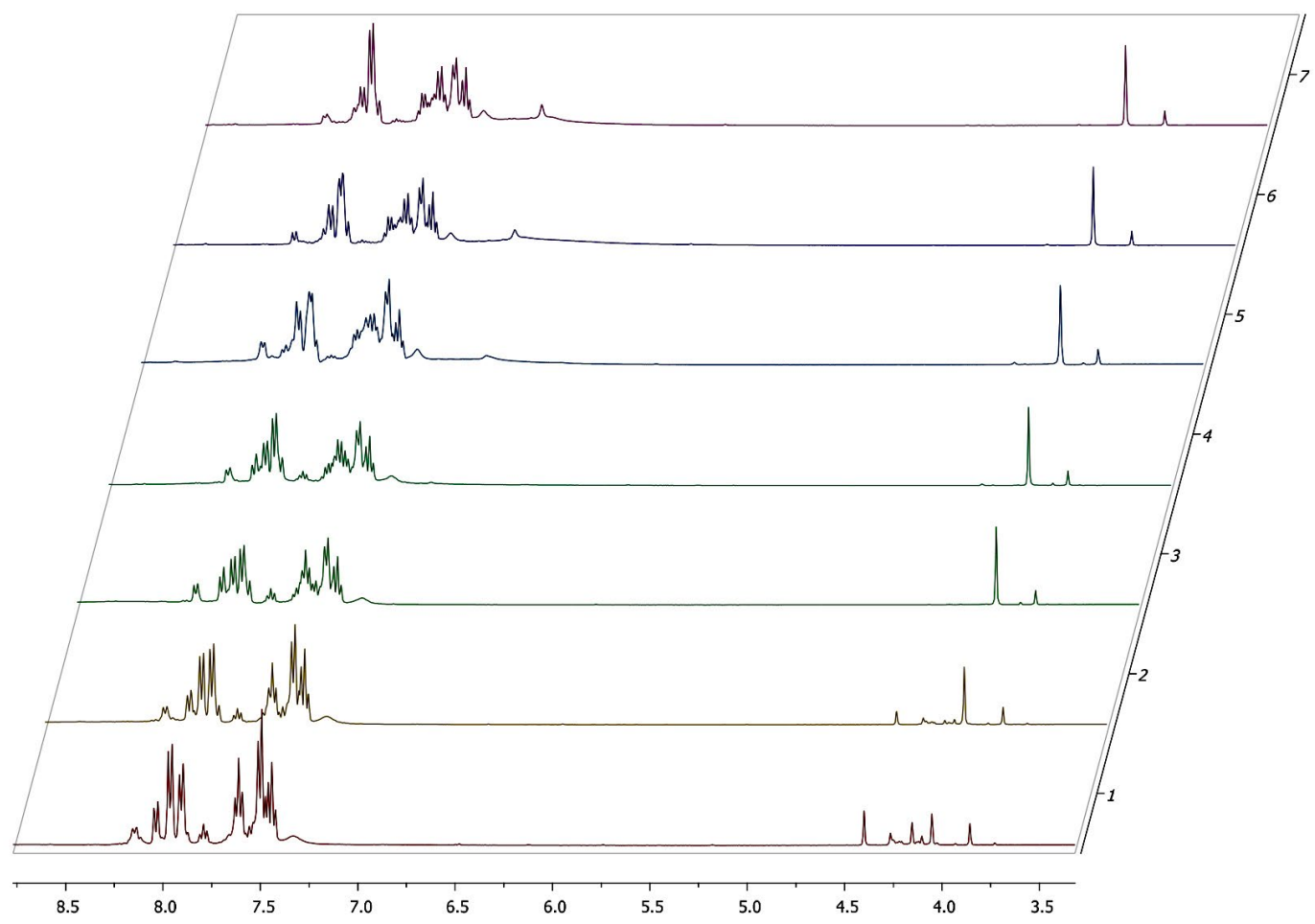

Figure 3. ${ }^{1} \mathrm{H}$ NMR monitoring of the progress of the reaction with time at 30 minute intervals 
step) which is a high energy species. Ts2 which is the second transition state has a lower energy hence it easily leads to the product. The HOMO-LUMO gaps showed the transition states have narrower HOMO-LUMO gaps compared to the starting materials, intermediate and products. The narrower HOMO-LUMO gaps confirms the ease of their transitions and hence their high reactivity.

\section{Acknowledgements}

I would like to thank the National Research Foundation (South Africa) for awarding me a postdoctoral fellowship.

\section{References}

1. L. Lu, H. Hu, H. Hou, B. Wang, Comput \& Theo Chem. 2013, 1015, 64-71. DOI:10.1016/j.comptc.2013.04.009

2. W. Kohn, A. D. Becke, R. G. Parr, J. Phys. Chem. 1996, 100, 12974-12980. DOI:10.1021/jp960669l

3. K. Burke, J. Chem. Phys. 2012, 136, 150901. DOI:10.1063/1.4704546

4. S. F. Sousa, P. A. Fernandes, M. J. Ramos, J. Phys. Chem. A 2007, 111, 10439-10452. DOI:10.1021/jp0734474

5. M. Korth, S. Grimme, J. Chem. Theory. Comput. 2009, 5, 993-1003. DOI:10.1021/ct800511q

6. K. E. Riley, B. T. Holt, K. M. Merz, J. Chem. Theory. Comput. 2007, 3, 407-433. DOI:10.1021/ct600185a

7. C. J. Cramer, D. G. Truhlar, Phys. Chem. Chem. Phys. 2009, 11, 10757-10816. DOI:10.1039/b907148b

8. L. Goerigk, S. Grimme, Phys. Chem. Chem. Phys. 2011, 13, 6670-6688. DOI:10.1039/c0cp02984j

9. J. Harris, Phys. Rev. A 1984, 29, 1648-1659.

DOI:10.1103/PhysRevA.29.1648

10. E. K. U. Gross, C. R. Proetto, J. Chem. Theory Comput. 2009, 5, 844-849. DOI:10.1021/ct9000334
11. A. D. Becke, J. Chem. Phys. 1993, 98, 1372-1377. DOI:10.1063/1.464304

12. A. D. Becke, J. Chem. Phys. 1993, 98, 5648-5652. DOI:10.1063/1.464913

13. R. H. Hertwig, W. Koch, Chem. Phys. Lett. 1997, 268, 345351. DOI:10.1016/S0009-2614(97)00207-8

14. G. E. Scuseria, V. N. Staroverov, Progress in the development of exchange-correlation functionals, in: C. E. Dykstra, G. Frenking, K .S. Kim, G. E. Scuseria (Eds.), Theory and Applications of Computational Chemistry: The First 40years, Amsterdam, Elsevier, 2005, pp. 669-724.

DOI:10.1016/B978-044451719-7/50067-6

15. A. Shiroudi, M. S. Deleuze, J. Mol. Model 2015, 21, 301. DOI:10.1007/s00894-015-2839-2

16. Y. Hu, L. Gao, Z. Dai, G. Sun, T. Zhang, S. Jia, Y. Dai, X. Zhang, J. Mol. Model 2016, 22, 56.

DOI:10.1007/s00894-016-2923-2

17. Q. Meng, F. Wang, J. Mol. Model 2016, 22, 60. DOI:10.1007/s00894-016-2930-3

18. R. Zhang, L. Ling, B. Wang, J. Mol. Model 2010, 16, 19111917. DOI:10.1007/s00894-010-0686-8

19. A. D. Becke, J. Chem. Phys. 1993, 98, 5648-5652. DOI:10.1063/1.464913

20. C. Lee, W. Yang, R. G. Parr, Phys. Rev. B 1988, 37, 785-789. DOI:10.1103/PhysRevB.37.785

21. P. J. Stephens, F. J. Devlin C. F. Chabalowski, M. J. Frisch, J. Phys. Chem. 1994, 98, 11623-11627. DOI:10.1021/j100096a001

22. W. J. Zhang, Y. Y. Zhu, D. H. Wei, M. S. Tang, J. Comput. Chem. 2012, 33, 715-722. DOI:10.1002/jcc.22906

23. Y. Zhu, Z. F. Chen, Z. J. Guo, Y. Wang, G. J Chen. J. Mol. Model. 2009, 15, 469-479. DOI:10.1007/s00894-008-0432-7

24. K. Fukui, Acc. Chem. Res. 1981, 14, 363-368. DOI:10.1021/ar00072a001

25. C. Gonzalez, H. B. Schlegel, J. Chem. Phys. 1989, 90, $2154-$ 2161. DOI: $10.1063 / 1.456010$

26. C. Gonzalez, H. B. Schlegel, J. Phys. Chem. 1990, 94, 55235527. DOI:10.1021/j100377a021

\section{Povzetek}

S teorijo gostotnega funkcionala smo z uporabo B3LYP / 6-31g (d) funkcionalnega in baznega seta preučevali mehanizem tvorbe $\mathrm{N}$ - (karbomilkarbamotiioil) benzamida in rezultate primerjali s podatki, dobljenimi iz časovnega spremljanja poteka reakcije $\mathrm{z}^{1} \mathrm{H}$ NMR spektroskopijo. Ugotovili smo, da za potek reakcije lahko predlagamo dve prehodni stanji: Ts1 (stopnja, ki določa hitrost reakcije) z izredno nestabilnimi delci, ki za nadaljevanje reakcije zahtevajo določeno orientacij in Ts2 z nižjo energijo, ki vodi do produkta. Računanje reakcijska pot je bila izvedena tudi z uporabo B3PW91 / 6-31G (d), M06 / 6-31G (d) in Wb97XD / 6- 31G (d) funkcionalnih in baznih setov, a dobljeni rezultati ne dopuščajo zanesljive napovedi reakcijske poti. 